\title{
In Vitro and in Vivo Activity of Allicin against Schistosoma Mansoni
}

Amany F. El Fakahany, Amina I. Abdelmaabood, Atef H. Abd El Hamid, Amira T. Morsi, Eman A. Abououf

Department of Parasitology,
Benha faculty of medicine,
Benha University, Egypt
Correspondence to: Amira T.
Morsi, Department of
Parasitology, Benha faculty of
medicine, Benha University,
Egypt
Email:
amirathanaabenha@gmail.com

Received: 1 June 2020

Accepted:11 June 2020

\begin{abstract}
:
Background: Garlic has a wide range of actions, including antibacterial, antiviral, antifungal, antiprotozoal and antihelminthic actions. This antiparasitic activity has been attributed to allicin, which is the main constituent of garlic. The aim: is to evaluate the potential therapeutic and/or prophylactic effects of allicin on S. mansoni. Method: Swiss albino mice strain CD1were infected with $S$. mansoni cercariae and sacrificed 40 days later to acquire the adult worms. These worms were collected by perfusion and placed in RPMI medium 1640 at $37^{\circ} \mathrm{C}$ before transferring to RPMI media containing 0 (control), 5, 10 and $100 \mu \mathrm{g} / \mathrm{ml}$ of allicin, where they were incubated for $48 \mathrm{~h}$ and monitored during this time to evaluate motility and mortality rate by means of stereomicroscope. Twenty male Swiss albino mice strain CD1were divided into two groups. One group was infected with $S$. mansoni cercariae and treated with allicin one week post infection. The second group was
\end{abstract} (control). Results: In vitro incubation of $S$. mansoni adult worms with allicin, showed a statistically high significant difference in comparison with control non-treated group. All worms showed slow movement after $48 \mathrm{~h}$ of incubation at concentration of $100 \mu \mathrm{g} / \mathrm{ml}$. No effect was noticed at allicin concentrations of 10 and $5 \mu \mathrm{g} / \mathrm{ml}$ at the end of the experiment. Administration of allicin to the infected mice had non- significant effect on the worm burden. Conclusion: allicin was effective against adult S. mansoni worms in vitro, but with no significant effect in vivo.

Keywords: Allicin; schistosomiasis; S.mansoni. 


\section{Introduction}

Human schistosomiasis is one of the most important parasitic diseases. It is reported to be endemic in 77 countries in tropical and subtropical regions, leading to infection of about 250 million individuals worldwide (1). The regions of the Middle East and North Africa represent high endemic spots for schistosomiasis, especially Egypt, which has about 7.2 million infected individuals (2). In Egypt, S.mansoni has nearly completely replaced S. haematobium in the Nile Delta especially after construction of the Aswan High Dam (3). The economic and health effects of schistosomiasis are considerable.

Treatment of schistosomiasis worldwide relies very heavily on praziquantel (PZQ). The effectiveness of this drug against schistosomes is well recognized, but evidences are now accumulating that PZQ is not effective in treating earlier stages of schistosomes (4). Meanwhile, in endemic areas, repeated chemotherapy has resulted in resistance (5). This has drawn the attention of many researchers to alternative drugs of plant origin which may be helpful in the treatment of schistosomiasis. Garlic is one of these plants. Garlic is known as an antiparasitic agent and this activity has been attributed to allicin, the main constituent of garlic (6). Although it is recommended for treating intestinal parasites in humans, few studies exist regarding the action of allicin on parasites. In this study we tried to evaluate the potential therapeutic and/or prophylactic effects of allicin on S.mansoni.

\section{Materials and Methods}

It is a prospective case control study. The study field work was the Schistosome Biological Supply Center (SBSC), Theodor Bilharz Research Institute (TBRI), Giza, Egypt. This study was carried in the period from July 2018 to October 2018.

Drug: Allicin was obtained in liquid form (Allimax liquid) purchased from www.iherb.com.

\section{In vitro susceptibility of S.mansoni to}

allicin: Adult S.mansoni worms were obtained by perfusion of the hepatic portal system of Swiss albino mice strain CD1 40 days after they were subjected to infection. The adult S.mansoni worms were washed in RPMI 1640(7) and then transferred to sterile tissue culture plates containing culture medium. 
Allicin was added at concentrations of O(control), 5, 10 and $100 \mu \mathrm{g} / \mathrm{ml}$. Each concentration was assayed in duplicate. The parasites were incubated for 48 hours and monitored during this time to evaluate motility and mortality rate by means of stereomicroscope. According to the motility criterion, the worms were considered to be dead when no movement was observed after two minutes of observation under a stereoscopic microscope (8).

\section{In vivo susceptibility of S.mansoni to allicin:}

Mice infection: Cercariae, from an Egyptian strain of S.mansoni, were isolated from laboratory-raised infected Biomphalaria snails (9). Cercaria shedding was induced by exposing infected water-immersed snails to light. The cercariae were collected and placed on cover slips and counted under a dissecting microscope. The mice were infected percutaneously with approximately $70 \pm 10$ S.mansoni cercariae (10).

\section{Mice grouping and experimental design}

Twenty adult male Swiss albino mice strain CD1 weighing 20-25gm inbred at Schistosome Biological Supply Center (SBSC), Theodor Bilharz Research Institute (TBRI), Giza, Egypt was used in throughout this study. Animals were housed in TBRI, Experimental Animal Unit. The mice were maintained under standard laboratory care $(25 \mathrm{C}$, with a relative humidity of 40-60\%, normal diet of commercial pellets and potable water. The animals were divided into two groups, with 10 mice per group as follow: Group 1: Infected non-treated (control). Group 2: Infected and treated with allicin one week post infection for 3 days (therapeutic effect on schistosomules). Allicin was administered to the mice at a dose of $8 \mathrm{mg} / \mathrm{Kg}$ by Intravenous route (11). On day 54 post-infection, the mice were scarified by decapitation and worms were recovered from the portal and mesenteric veins via vascular perfusion (12). The perfused saline and blood drained from the portal vein were recovered in a beaker and left to form sediment. The supernatant was removed, and the precipitate was washed twice with saline. After washing, the recovered worms were counted using a magnifying lens.

\section{Statistical analysis}

These data were tabulated, coded then analyzed using the computer program SPSS version 20. Student's t-test used to compare the mean of two groups of statistical (parametric) data. Fisher exact test (FET) was used forinter-group comparison of categorical data. The $\mathrm{P}$ value $<0.05$ was considered statistically 
significant and $\mathrm{P}$ value $<0.0001$ was considered highly significant while $\mathrm{P}$ value $>0.05$ was considered insignificant in all analyses.

Ethical considerations: The study was approved from ethical committee at Faculty of Medicine, Benha University. As well, animal handling and all procedures were done in agreement with the worldwide ethical guidelines.

\section{Results}

As shown in (table1), in vitro incubation of S.mansoni adult worms with allicin, at concentration of $100 \mu \mathrm{g} / \mathrm{ml}$, showed a statistically high significant difference in comparison with control non-treated group. All worms showed slow movement after $48 \mathrm{~h}$. No effect was noticed at allicin concentrations of 10 and $5 \mu \mathrm{g} / \mathrm{ml}$ at the end of the experiment. As shown in (table 2), the results show that there is a slight decrease in the mean number of male and female worms observed in the treated group which is non-significant statistically ( $\mathrm{p}$ value >0.05). However, there is an increase in the mean number of couple worms and total worm burden observed in the treated groups which is nonsignificant statistically ( $\mathrm{p}$ value $>0.05$ )

Table (1): In vitro schistosomicidal effect of allicin on S.mansoni adult worms

\begin{tabular}{|c|c|c|c|c|c|c|c|c|}
\hline Groups & $\begin{array}{l}\text { No. of } \\
\text { worms }\end{array}$ & $\begin{array}{c}\text { Incubation } \\
\text { period }\end{array}$ & Normal & $\begin{array}{r}\text { Adult worm } \\
\text { No. }\end{array}$ & ctivity & Dead & $\begin{array}{l}\text { P value } \\
\text { with } \\
\text { control } \\
\text { group }\end{array}$ & $\begin{array}{c}\text { P value of } \\
\text { different } \\
\text { times in the } \\
\text { same group }\end{array}$ \\
\hline $\begin{array}{l}\text { Healthy } \\
\text { control }\end{array}$ & 14 & $\begin{array}{l}24 \text { hours } \\
48 \text { hours }\end{array}$ & $\begin{array}{l}14(100 \%) \\
14(100 \%)\end{array}$ & $\begin{array}{l}0(0 \%) \\
0(0 \%)\end{array}$ & $\begin{array}{l}0(0 \%) \\
0(0 \%)\end{array}$ & $\begin{array}{l}0(0 \%) \\
0(0 \%)\end{array}$ & & \\
\hline $100 \mu \mathrm{g}$ & 12 & 24 hours & $12(100 \%)$ & $0(0 \%)$ & $0(0 \%)$ & $0(0 \%)$ & & \\
\hline $\begin{array}{l}\text { Allicin/ml } \\
\text { media }\end{array}$ & & 48 hours & $0(0 \%)$ & $12(100 \%)$ & $0(0 \%)$ & $0(0 \%)$ & $<0.001 * *$ & $<0.001 * *$ \\
\hline $10 \mu \mathrm{g}$ & 13 & 24 hours & $13(100 \%)$ & $0(0 \%)$ & $0(0 \%)$ & $0(0 \%)$ & & \\
\hline $\begin{array}{l}\text { Allicin/ml } \\
\text { media }\end{array}$ & & 48 hours & $13(100 \%)$ & $0(0 \%)$ & $0(0 \%)$ & $0(0 \%)$ & & \\
\hline $5 \mu \mathrm{g}$ & 10 & 24 hours & $10(100 \%)$ & $0(0 \%)$ & $0(0 \%)$ & $0(0 \%)$ & & \\
\hline $\begin{array}{l}\text { Allicin/ml } \\
\text { media }\end{array}$ & & 48 hours & $10(100 \%)$ & $0(0 \%)$ & $0(0 \%)$ & $0(0 \%)$ & & \\
\hline
\end{tabular}

Media: RPMI 1640 with L-Glutamine.

** $\mathrm{P}$ value <0.001: highly significant difference. 
Benha medical journal vol. 37, issue 3, 2020

Table (2): Effect of allicin on S.mansoni mature worm burden in infected mice

\begin{tabular}{|c|c|c|c|c|}
\hline Groups & $\begin{array}{l}\text { No of couples } \\
\text { mean } \pm \text { SD }\end{array}$ & $\begin{array}{l}\text { No of male worms } \\
\text { mean } \pm \text { SD }\end{array}$ & $\begin{array}{l}\text { No of female } \\
\text { worms } \\
\text { mean } \pm \text { SD }\end{array}$ & $\begin{array}{l}\text { Total worm burden } \\
\text { mean } \pm \text { SD } \\
(P \text { value })\end{array}$ \\
\hline & (P value) & (P value) & (P value) & \\
\hline Control group & $5.63 \pm 2.13$ & $2.38 \pm 0.92$ & $0.75 \pm 0.46$ & $14.38 \pm 4.31$ \\
\hline $\begin{array}{l}\text { Allicin treated } \\
\text { group } 1 \text { week } \\
\text { post infection }\end{array}$ & $\begin{array}{l}6.57 \pm 2.44 \\
(0.44)\end{array}$ & $\begin{array}{l}1.57 \pm 1.27 \\
(0.18)\end{array}$ & $\begin{array}{l}0.43 \pm 0.54 \\
(0.22)\end{array}$ & $\begin{array}{l}15.14 \pm 4.02 \\
(0.73)\end{array}$ \\
\hline
\end{tabular}

Control group: infected not treated.

Allicin treated group 1 week post infection: treated with allicin ( $8 \mathrm{mg} / \mathrm{Kg}$ by intravenous route) one week post infection (therapeutic effect on schistosomules 


\section{Discussion:}

Treatment of schistosomiasis worldwide relies very heavily on PZQ. However, any parasitic treatment based on the use of a single drug has serious concerns regarding the onset of resistance (13). Another possible cause of treatment failure, apart from resistance, is the inefficacy of PZQ in treating earlier stages of schistosomes (14).

In the last few years, there is an obvious increase in searching for anti-parasitic drugs from natural sources especially from plants. Many plant species have been used throughout the world in traditional medicine for the treatment of helminths (15), but few plants have been screened for activity against S.mansoni (16). One of these compounds is allicin. Allicin is the most biologically active compound of garlic "heart of garlic" (17).

Allicin is thought to be responsible for garlic antimicrobial effects. However, not all garlic preparations are standardized, and even standardized brands may vary with respect to the amount of allicin they provide (18). So we used pure allicin in this study.

In the present work, we studied the potential effect of allicin on S.mansoni in vitro and in experimental mice. In vitro experiment, the efficacy was evaluated depending on motor activity and mortality rate of the worms. In vivo experiment, the efficacy was evaluated depending on worm burden. According to our results, in vitro incubation of S.mansoni adult worms with allicin, showed decrease motility within $48 \mathrm{~h}$ at a concentration of $100 \mu \mathrm{g} / \mathrm{ml}$ of allicin. Allicin was found to have no effect on adult S.mansoni incubated in vitro at concentrations of 10 and $5 \mu \mathrm{g} / \mathrm{ml}$. To the best of our knowledge, only one research discussed the effect of allicin in vitro on S.mansoni adult worm. In contradiction with our result, (19) reported that no worm mortality was observed at allicin concentrations 5, 10, 15 and $20 \mathrm{mg} / \mathrm{ml}$ within $2 \mathrm{~h}$. This contradiction with our result may be due to shorter time of observation in their work (only $2 \mathrm{~h}$ post treatment). The mechanism of action behind allicin's effectiveness has been attributed to its reaction with the sulfhydryl-group of cysteine via a disulfide exchange-like reaction (20). The present study conducted in experimental mice showed that allicin reduced the female and male worm count and increased couple worm and total worm count, but all were non-significant statistically indicating that allicin has no significant effect on worm burden .To the best of our knowledge, only one research discussed the effect of allicin on S.mansoni infected mice. In contradiction with our 
result, (21) reported that allicin significantly reduced the mean worm count (20.33\%) compared to the control. This discrepancy may be due to different dose, different timing and different route of allicin administration.(21) administered allicin $(0.5 \mu \mathrm{M} /$ mouse $=81 \mu \mathrm{g} /$ mouse $=$ $3.25 \mathrm{mg} / \mathrm{Kg}$ ) daily till 55 day post infection, in the prophylactic group treatment started 1 week before infection and in another group started on the first day post infection, by oral gavage.

The unexpected weak effect of allicin on S.mansoni infection in mice after its good results in vitro is likely because in the blood circulation, allicin is rapidly metabolized to allyl-mercaptoglutathion, diallyl disulfide, diallyltrisulfide, and other various thiosulfinate products (22). These metabolites may be inactive against S.mansoni.There is a possibility that allicin is reacting with other free sulfhydryl groups present in a variety of serum proteins (22).However, it is also possible that allicin is modulating the immune response of the host. Impairment of $\mathrm{TNF} \alpha$ secretion massively influences the regulation of the immune-response. (23) reported that allicin inhibits the release of TNF $\alpha$-dependent proinflammatory cytokines in intestinal epithelia decreasing intestinal inflammation.
Conclusion: Our study revealed that allicin has a potent effect on mature S.mansoni worms in vitro, but with weak effect on S.mansoni worms in vivo. Further in vivo studies are needed to detect allicin activity against S.mansoni.

\section{References}

1. Hotez PJ, Savioli L, Fenwick A. Neglected tropical diseases of the Middle East and North Africa: review of their prevalence, distribution, and opportunities for control. PLoS Negl Trop Dis. 2012;6(2).

2. Mota SGR. Identificação e caracterização de inibidores da enzima glicose-6-fosfato isomerase de Leishmania mexicana. 2018;

3. El Naga IFA, Eissa MM, Mossallam SF, ElHalim SIA. Inheritance of Schistosoma mansoni infection incompatibility in Biomphalaria alexandrina snails. Mem Inst Oswaldo Cruz. 2010;105(2):149-54.

4. Cioli D. Chemotherapy of schistosomiasis: an update. Parasitol Today. 1998;14(10):418-22.

5. Kenworthy JD, Ye P, Wu GC, Yu H, Shi $\mathrm{YJ}$, Li $\mathrm{H}$, et al. Field evaluation of a test for praziquantel resistance in Schistosoma sp. Vet Parasitol. 2003;113(1):83-7.

6. Ankri S, Mirelman D. Antimicrobial properties of allicin from garlic. Microbes Infect. 1999;1(2):125-9.

7. Pellegrino J, Brener Z. Method for isolating schistosome granulomas from mouse liver. J Parasitol. 1956;42(6).

8. Ramalhete C, Magalhães LG, Rodrigues V, Mulhovo S, Da Silva Filho AA, Ferreira M-JU. In vitro schistosomicidal activity of balsaminol $\mathrm{F}$ and karavilagenin C. Planta Med. 2012;78(18):1912-7.

9. Schubert M. Conditions for Drug Testing in Experimental Schistosomiasis Mansoni in Mice1. Am J Trop Med Hyg. 1948;1(1):121-36.

10. Frandsen F. Cultivation of schistosomes for chemotherapeutic studies. Acta Pharmacol Toxicol (Copenh). 1981;49:118-22. 
11. Shadkchan Y, Shemesh E, Mirelman D, Miron T, Rabinkov A, Wilchek M, et al. Efficacy of allicin, the reactive molecule of garlic, in inhibiting Aspergillus spp. in vitro, and in a murine model of disseminated aspergillosis. J Antimicrob Chemother. 2004;53(5):832-6.

12. Duvall RH, DeWitt WB. An improved perfusion technique for recovering adult schistosomes from laboratory animals. Am J Trop Med Hyg. 1967;16(4):483-6.

13. Castro AP, Mattos ACA, Souza RLM, Marques MJ, Santos MHD. Medicinal plants and their bioactive constituents: a review of bioactivity against Schistosoma mansoni. J Med Plants Res. 2013;7:1515-22.

14. Doenhoff MJ, Cioli D, Utzinger J. Praziquantel: mechanisms of action, resistance and new derivatives for schistosomiasis. Curr Opin Infect Dis. 2008;21(6):659-67.

15. Fennell CW, Lindsey KL, McGaw LJ, Sparg SG, Stafford GI, Elgorashi EE, et al. Assessing African medicinal plants for efficacy and safety: pharmacological screening and toxicology. J Ethnopharmacol. 2004;94(2-3):205-17.

16. Sanderson L, Bartlett A, Whitfield PJ. In vitro and in vivo studies on the bioactivity of a ginger (Zingiber officinale) extract towards adult schistosomes and their egg production. J Helminthol. 2002;76(3):241-7.

17. Josling P. Allicin the Heart of Garlic. NWI Publishing Callahan Florida; 2003.
18. Trio PZ, You S, He X, He J, Sakao K, Hou $\mathrm{D}-\mathrm{X}$. Chemopreventive functions and molecular mechanisms of garlic organosulfur compounds. Food Funct. 2014;5(5):833-44.

19. Lima CMBL, Freitas FI de S, Morais LCSL de, Cavalcanti MG dos S, Silva LF da, Padilha RJR, et al. Ultrastructural study on the morphological changes to male worms of Schistosoma mansoni after in vitro exposure to allicin. Rev Soc Bras Med Trop. 2011;44(3):32730 .

20. Rabinkov A, Miron T, Konstantinovski L, Wilchek M, Mirelman D, Weiner L. The mode of action of allicin: trapping of radicals and interaction with thiol containing proteins. Biochim Biophys Acta (BBA)-General Subj. 1998;1379(2):233-44.

21. Metwally DM, Al-Olayan EM, Alanazi M, Alzahrany SB, Semlali A. Antischistosomal and anti-inflammatory activity of garlic and allicin compared with that of praziquantel in vivo. BMC Complement Altern Med. 2018;18(1):135.

22. Freeman F, Kodera Y. Garlic chemistry: stability of S-(2-propenyl)-2-propene-1sulfinothioate (allicin) in blood, solvents, and simulated physiological fluids. J Agric Food Chem. 1995;43(9):2332-8.

23. Lang A, Lahav M, Sakhnini E, Barshto cack I, Fidder HH, Avidan B, et al. Allicin inhibits spontaneous and TNF- $\alpha$ induced secretion of proinflammatory cytokines and chemokines from intestinal epithelial cells. Clin Nutr. 2004;23(5):1199-208.

To cite this article: Amany F. El Fakahany, Amina I. Abdelmaabood, Atef H. Abd El Hamid, Amira T. Morsi, Eman A. Abououf, In vitro and In vivo Activity of Allicin against Schistosoma mansoni. BMFJ2020;37(3):578-585, DOI: 10.21608/bmfj.2020.33135.1278 
Benha medical journal vol. 37, issue 3, 2020 